\title{
Oclusão de ramo venoso da retina associado ao uso de infliximabe: relato de caso
}

\author{
Branch retinal vein occlusion following infliximab treatment: case report
}

Bruno Diniz ${ }^{1}$, Carolina Pelegrini Barbosa ${ }^{1}$, Caio Vinicius Regatieri ${ }^{1}$, Eduardo B. Rodrigues ${ }^{1}$

\section{RESUMO}

Descrevemos o caso de uma paciente, de 53 anos, com quadro de oclusão de ramo venoso da retina após receber seis infusões de infliximabe (3 mg/kg/dose), para tratamento de artrite reumatóide. A investigação clínica e laboratorial sobre distúrbios de coagulação, cardiopatias e sinais de hipertensão arterial crônica foi negativa. A relação temporal do uso de infliximabe e o desenvolvimento do quadro de oclusão de ramo pode indicar um possível efeito adverso da medicação.

Descritores: Artrite reumatóide/quimioterapia; Anticorpos monoclonais/administração \& dosagem; Anticorpos monoclonais/efeitos adversos; Oclusão da veia retiniana/induzido quimicamente; Relato de caso

\begin{abstract}
A case of a 53 year-old female patient who developed branch retinal vein occlusion after six $3 \mathrm{mg} / \mathrm{kg}$ Infliximab infusions for rheumatoid arthritis treatment is reported. Hematological disorders, cardiopathy and chronic systemic hypertension evaluation were negative. The relationship between the infliximab therapy and the development of retinal vein occlusion raises awareness of the possibility of a potential side effect of this medication.
\end{abstract}

Keywords: Rheumatoid arthritis/drug therapy: Antibodies, monoclonal/administration \& dosage; Antibodies, monoclonal/adverse effects; Retinal vein occlusion/chemically induced; Case reports

\section{INTRODUÇÃO}

O papel do fator de necrose tumoral alfa (TNF- $\alpha$ ) e famílias do receptor de TNF na patogênese de doenças inflamatórias, neoplásicas e autoimunes é bem estabelecido por estudos experimentais ${ }^{(1)}$. Além disso, sua ação é apoiada pela eficácia clínica de inibidores de TNF- $\alpha$, tais como o infliximabe em estudos randomizados controlados para o tratamento de várias doenças, incluindo artrite reumatóide (AR) e doença de Crohn ${ }^{(2)}$.

Infliximabe (Remicade, Centocor, Horsham, PA, E.U.A.) é uma imunoglobulina humana lgG1 quimérica com um fragmento Fv variável de rato com alta afinidade ao TNF- $\alpha$ e capacidade de neutralização ${ }^{(1)}$. Infliximabe é altamente eficaz e aprovado pelo Departamento de Alimentos e Drogas dos Estados Unidos da América (FDA) no tratamento de doenças inflamatórias, tais como AR e doença de $\mathrm{Crohn}^{(2,3)}$. No entanto, as doses endovenosas utilizadas atualmente podem causar efeitos adversos tais como reações anafiláticas, reativação de tuberculose pulmonar, abscesso de partes moles, hepatotoxicidade e eventos tromboembólicos. Relatamos um caso de oclusão de ramo venoso da retina que ocorreu concomitante ao uso do infliximabe, utilizado para tratamento de artrite reumatóide.

\section{RELATO DE CASO}

Paciente do sexo feminino, 53 anos, encaminhada ao ambulatório de Retina e Vítreo da Universidade Federal de São Paulo com queixa de baixa acuidade visual central e defeito do campo visual inferior do olho direito. Relatava que os sintomas haviam iniciado cerca de quatro horas após ter sido submetida à infusão intravenosa de infliximabe, para tratamento de artrite reumatóide. Negava sintomas associados ou doenças oculares prévias.
Apresentava história de artrite reumatóide há 20 anos, em acompanhamento na disciplina de reumatologia da Universidade Federal de São Paulo. Estava em uso de prednisona oral $5 \mathrm{mg} / \mathrm{dia}$ há 6 meses e o uso de terapia biológica, infliximabe, foi indicado pela equipe da disciplina de reumatologia, devido ao não controle clínico apenas com corticóide oral. A paciente não apresentava outras doenças sistêmicas associadas.

Foram realizadas, ao todo, seis infusões do medicamento, com dose de $3 \mathrm{mg} / \mathrm{kg}$ em intervalos de dois meses. Nenhuma intercorrência foi relatada, exceto por episódios de tosse seca e dispnéia associadas ao uso do medicamento. As aferições de pressão arterial durante as consultas reumatológicas demonstravam níveis dentro da normalidade. Nenhum sintoma oftalmológico foi referido, até a última infusão de infliximabe.

Ao exame oftalmológico, um dia após a infusão da sexta dose do medicamento, apresentava acuidade visual com melhor correção de 0,5 no olho direito e 1,0 no esquerdo (medida na tabela de Snellen). Os reflexos pupilares direto e consensual eram presentes e simétricos. No exame de fundo de olho à direita foi diagnosticada oclusão de ramo da veia temporal superior, associada a edema cistóide de mácula, confirmado pela tomografia de coerência óptica (Figura 1). No olho esquerdo não foram observadas alterações retinianas.

A conduta oftalmológica inicial foi expectante, entretanto a paciente foi encaminhada para investigação clínica sobre distúrbios de coagulação, hiperlipidemia, cardiopatias e sinais de hipertensão arterial crônica. Foram realizados hemograma completo, pesquisa de deficiência de proteína $C$ e proteína $S$, deficiência de antitrombina III, anticorpo antifosfolípede, anticardiolipina, coagulograma completo, triglicérides, colesterol total e frações, eletro- 

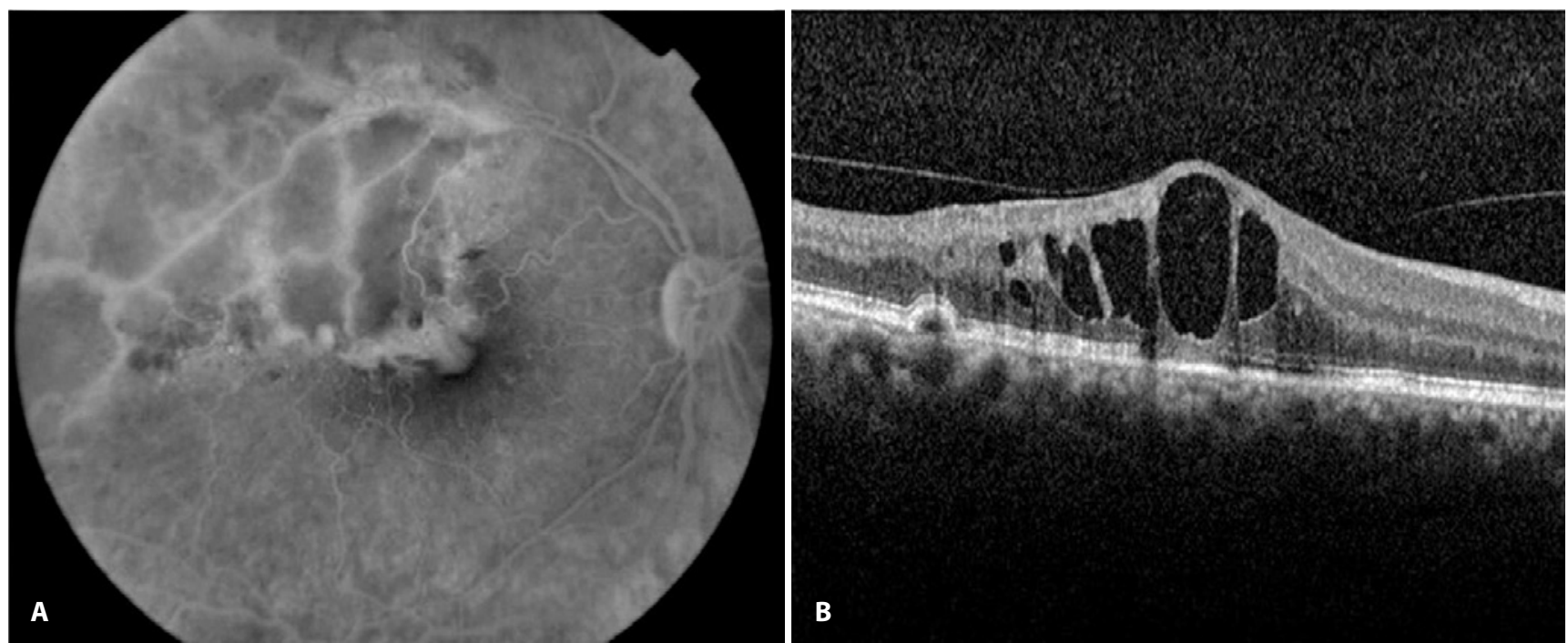

Figura 1. A) Angiografia fluoresceínica do olho direito mostrandoáreas de hiperfluorescência por vazamento vascular na região temporal superior macular, correspondente à área de oclusão venosa; B) Tomografia de coerência óptica evidenciando cistos intrarretinianos no edema macular secundário à oclusão.

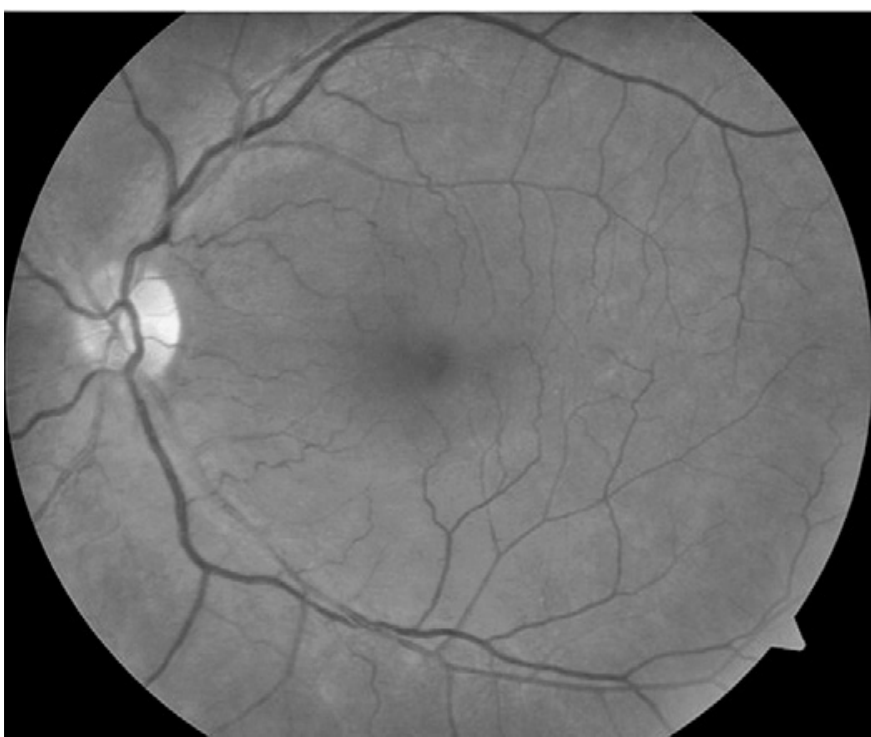

Figura 2. Retinografia do olho esquerdo mostrando vasos retinianos de aspecto e calibre preservados.

cardiograma e ultrassom de carótidas, todos normais. Neste momento, foi introduzido etanercept $25 \mathrm{mg}$ 2X/semana para a paciente, em substituição ao infliximabe.

Quatro meses após o episódio, foi diagnosticada neovascularização de retina, próxima à arcada temporal superior, sendo indicada fotocoagulação nesta região. A paciente evoluiu com regressão dos neovasos, redução do edema macular e melhora parcial da acuidade visual, e cerca de seis meses após terapia com laser, apresentava acuidade de 0,8.

\section{DISCUSSÃO}

Atualmente, são inúmeros os avanços nos tratamentos envolvendo anticorpos monoclonais, entre eles o infliximabe. Sabe-se que ele é útil no tratamento da doença de Crohn e na artrite reumatóide ${ }^{(3)}$. Mais recentemente, estudos controlados têm mostrado sua efetividade em casos como psoríase, artrite psoriática e espondilite anquilosante ${ }^{(4)}$. Além disso o uso sistêmico é promissor para tratamento de doenças que atingem o olho como sarcoidose, síndrome de Sjögren e Behçet. O uso intravítreo de infliximabe mostrou-se eficaz no tratamento de inflamação ocular e de neovascularização de coroide ${ }^{(1)}$

Apesar dos resultados positivos, o seu uso está relacionado a alguns eventos adversos. Imediatamente após infusão endovenosa o paciente pode apresentar cefaléia, mialgia, poliartralgia, febre e leucocitose, consistindo em uma reação aguda a infusão da droga ${ }^{(5)}$. Além disso, agentes anti-TNF- $\alpha$ têm importante papel imunomodulador, mediando processos inflamatórios e regulando a resposta imunocelular ${ }^{(1)}$. Sendo assim, estudos revelam que pacientes tratados com anti-TNF- $\alpha$ são mais susceptíveis a infecções, sendo tuberculose a principal(6). Endoftalmite endógena e neurite óptica tóxica bilateral também foram relacionados ao uso sistêmico de infliximabe ${ }^{(7)}$

Neste caso relatamos uma paciente em uso de infliximabe para tratamento de artrite reumatóide que apresentou fenômeno trombótico, como evento adverso. As oclusões venosas retinianas podem estar associadas à hipertensão arterial, diabetes mellitus e história de tabagismo. Além disso, hiperviscosidade sanguínea e doenças trombofílicas também podem causar quadro de oclusão venosa retiniana.

Existem outros relatos de oclusão venosa retiniana e trombose venosa profunda em pacientes em uso infliximabe sistêmico para tratamento de doença de $\mathrm{Crohn}^{(8)}$. Entretanto sabe-se que as doenças inflamatórias intestinais são condições protrombóticas que por si só podem gerar quadros de oclusão venosa ${ }^{(9)}$. Já o risco de tromboembolismo em pacientes com artrite reumatóide é pouco compreendido. Os pacientes com doença ativa podem exibir níveis elevados de autoanticorpos como anticardiolipina e antifosfolípede. Por outro lado, estes pacientes podem ter risco reduzido de fenômenos tromboembólicos já que em geral são mais jovens, tem índice de massa corpórea mais baixo e frequentemente recebem anti-inflamatórios não esteroidais ${ }^{(10)}$

A etiologia da oclusão de ramo venoso retiniano neste caso não é clara. A investigação clínica foi negativa para as principais patologias associadas às oclusões retinianas e não foram detectados sinais de esclerose arteriolar e cruzamentos patológicos dos vasos retinianos (Figura 2). Houve associação temporal entre o uso do inflixi- 
mabe e o desenvolvimento de oclusão, entretanto, não é possível estabelecer clara relação causal.

\section{CONCLUSÃO}

A oclusão de ramo venoso retiniano pode ser um possível evento adverso do infliximabe. Este relato mostra que existe uma forte associação entre o uso desta droga e o efeito trombótico, uma vez que outras causas sistêmicas foram excluídas.

\section{REFERÊNCIAS}

1. Rodrigues EB, Farah ME, Maia M, Penha FM, Regatieri C, Melo GB, et al. Therapeutic monoclonal antibodies in ophthalmology. Prog Retin Eye Res. 2009;28(2):117-44.

2. Edrees AF, Misra SN, Abdou NI. Anti-tumor necrosis factor (TNF) therapy in rheumatoid arthritis: correlation of TNF-alpha serum level with clinical response and benefit from changing dose or frequency of infliximab infusions. Clin Exp Rheumatol. 2005; 23(4):469-74
3. Comerford LW, Bickston SJ. Treatment of luminal and fistulizing Crohn's disease with infliximab. Gastroenterol Clin North Am. 2004;33(2):387-406, xi.

4. Braun J, Brandt J, Listing J, Zink A, Alten R, Burmester G, et al. Long-term efficacy and safety of infliximab in the treatment of ankylosing spondylitis: an open, observational, extension study of a three-month, randomized, placebo-controlled trial. Arthritis Rheum. 2003; 48(8):2224-33

5. Hanauer SB. Review article: safety of infliximab in clinical trials. Aliment Pharmacol Ther. 1999;13 Suppl 4:16-22; discussion 38.

6. Su CG, Lichtenstein GR. Influence of immunogenicity on the long-term efficacy of Infliximab in Crohn's disease. Gastroenterology. 2003;125(5)1544-46.

7. ten Tusscher MP, Jacobs PJ, Busch MJ, de Graaf L, Diemont WL. Bilateral anterior toxic optic neuropathy and the use of infliximab. BMJ. 2003;326(7389):579.

8. Veerappan SG, Kennedy M, O'Morain CA, Ryan BM. Retinal vein thrombosis following infliximab treatment for severe left-sided ulcerative colitis. Eur J Gastroenterol Hepatol. 2008;20(6):588-89.

9. Grainge MJ, West J, Card TR. Venous thromboembolism during active disease and remission in inflammatory bowel disease: a cohort study. Lancet. 2010;375(9715):657-63.

10. Niki Y, Matsumoto H, Hakozaki A, Mochizuki T, Momohara S. Rheumatoid arthritis: a risk factor for deep venous thrombosis after total knee arthroplasty? Comparative study with osteoarthritis. J Orthop Sci. 2010;15(1):57-63.

\section{Congresso do Hospital São Geraldo}

\section{3 a 05 de novembro de 2011}

Belo Horizonte - MG

\section{- Informações:}

Rhodes Eventos

Tel.: (31) 3227-8544

Site: http://www.rhodeseventos.com.br 